NMP-EHA-92-0063

\title{
MAXIMUM UNCERTAINTY ESTIMATION FOR THE HB-LINE VENTILATION INSTRUMENTATION READINGS (U)
}

by D. R. Melton

NNP-EHA- $-92-0063$

Westinghouse Savannah River Company

DE93 005684

Savannah River Site

Aiken, South Carolina 29808

Other Authors:

This paper was prepared in connection with work don under Contract No. DE-AC09-89SR18035 with the U. S. Department of Energy. By acceptance of this paper, the publisher and/or recipient acknowledges the U. S. Government's right to retain a nonexclusive, royalty-free license in and to any copyright covering this paper, along with the right to reproduce and to authorize others to reproduce all or part of the copyrighted paper.
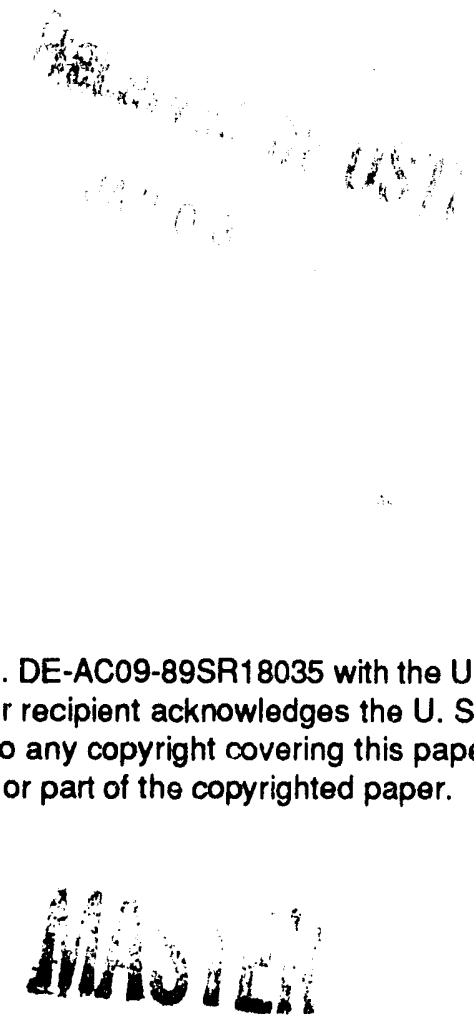


\section{DISCLAIMER}

This report was prepared as an account of work sponsored by an agency of the United States Govemment. Neither the United States Government nor any agency thereof, nor any of their employees, makes any warranty, express or implied, or assumes any legal liability or responsibility for the accuracy, completeness, or usefulness of any information, apparatus, product, or process disclosed, or represents that its use would not infringe privately owned rights. Reference herein to any specific commercial product, process, or service by trade name, trademark, manufacturer, or otherwise does not necessarily constitute or imply its endorsement, recommendation, or favoring by the United States Government or any agency thereof. The views and opinions of authors expressed herein do not necessarily state or reflect those of the United States Government or any agency thereof.

This report has been reproduced directly from the best available copy.

Available to DOE and DOE contractors from the Office of Scientific and Technical Information, P.O. Box 62, Oak Ridge, TN 37831; prices available from (615) 576-8401, FTS 626-8401.

Available to the public from the National Technical Information Service, U.S. Department of Commerce, 5285 Port Royal Rd, Springfield, VA 22161. 
WESTINGHOUSE SA VANNAH RIVER COMPANY

INTER-OFFICE MEMORANDUM

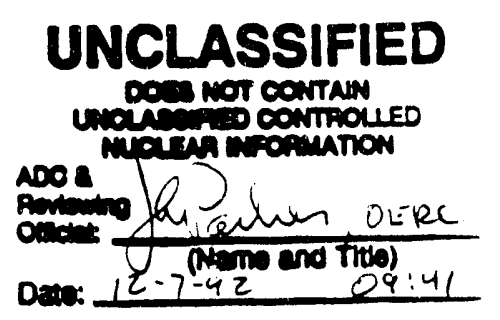

NMP-EHA-920063

December 4, 1992

TO: J. S. Evans, 707-F

FROM:

D. R. Melton, 221-10H DRpetto

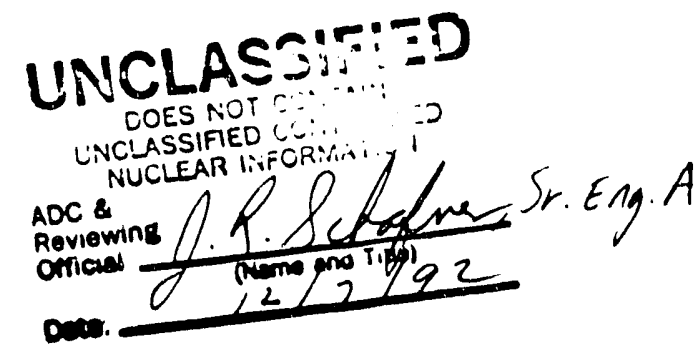

CONCURRENCE: W. D. Stephens, 221-HBI, wostoh

\section{MAXIMUM UNCERTAINTY ESTIMATION FOR THE HB-LINE VENTILATION INSTRUMENTATION READINGS (U)}

The HB-Line building vacuum instrumentation measures the differential pressure between atmosphere and the corridors within the hardened structure. The building vacuum instrumentation loop consists of three Foxboro 834 Series Transmitters, a Moore 380F Adder/Subtractor Module, and a Moore 350 Series Controller. The 834 Series Transmitter is an electronic instrument that measures differential pressure and converts this measurement to a proportional milliampere signal. The building vacuum differential pressure transmitters have a measurement span of -1.5 to 1.5 inches of water column. The differential pressure measurement is converted to a 4 to 20 milliampere output signal. The 834 Series Transmitters can be calibrated to an accuracy of 01 percent of the measurement span. The differential pressure transmitters are calibrated by simulating a pneumatic signal with a Loveland Calibrator connected to the inlet pressures taps of the transmitter and adjusting the transmitter output signal to the corresponding milliampere signal within a tolerance of 1 percent of the output span $( \pm 0.16 \mathrm{ma})$. The Moore 380F Adder/Subtractor Module can receive two or three input signals (1-5 volts $\mathrm{dc}$ ) and provides a current output signal (4 to 20 milliampere) proportional to the sum and/or difference of the input signals. The inputs can be either added or subtracted by means of field changeable jumper on the circuit board 
NMP-EHA-920063

December 4, 1992

Page 2

depending on the application. The Adder/Subtractor Module combines the signals from the three differential pressure transmitters using a weighted sum method to provide an averaged uutput signal. The Moore 380F Adder/Subtractor Module can be calibrated to an accuracy of 0.1 percent of the output span. The Adder/Subtractor Module is calibrated by simulating a current input signal using a Ronan Calibrator and adjusting the module output signal to corresponding milliampere signal within a tolerance of 1 percent of the output span $( \pm 0.16 \mathrm{ma})$. This output signal, representing the differential pressure between the building and atmosphere, is sent to the Moore 350 Series Controller in the Instrument Control Room where it is displayed on a bargraph. The Moore 350 Series Controllers are equipped with two 4 inch vertical scale bargraph displays for setpoint and process signals. The VertiGage bargraph is a multi-segmented gas discharge (neon tube type) lamp. There are 201 segments in each bargraph. The first segment below the end of the scale is always lit to indicate the bargraph is working. The 200 on-scale segments provide a display whose height is proportional to the setpoint or process signals. Each fully lit segment represents a 0.5 percent of scale. The bargraph display is calibrated by simulating a current input signal using a Ronan Calibrator and verifying the height of the bargraph display corresponds to the input signal within a tolerance of 1 percent of the display scale $\left({ }^{ \pm} 0.03\right.$ inches of water column). The building vacuum controller bargraph display has a lens covering with a scale marked in increments of 0.05 inches of water column with a range from -1.5 to 1.5 inches of water column. Tae resolution of the bargraph display is equivalent to 0.015 inches of water column. The components of the building vacuum instrumentation loop are calibrated semiannually.

The glovebox vacuum instrumentation measures the differential pressure between the process room and the glovebox. The glovebox vacuum instrumentation loops consist of Foxboro 834 Series Transmitters and Moore 350 Series Controllers. The glovebox vacuum differential pressure transmitters have a measurement span of 0 to -2 inches of water column. A glovebox vacuum controller bargraph has a lens covering with a scale marked in increments of 0.05 inches of water column with a range from 0 to -2 inches of water column. The resolution of the bargraph display is equivalent 
to 0.01 inches of water column. The components of the glovebox vacuum instrumentation loop are calibrated semiannually.

The canyon exhaust tunnel vacuum instrumentation measures the differential pressure between the 1 st level of the Canyon center section and the Canyon exhaust tunnel. Tire Canyon exhaust tunnel vacuum instrumentation loop consists of a Foxboro 834 Series

Transmitter and a Moore Series 3601 Recorder. The Canyon exhaust tunnel vacuum differential pressure transmitter has a measurement span of +1 to -4 inches of water column. The Model Series 3601

Recorder provides a direct readout and a permanent recording of the input signals. The chart magazine holds a 4 " wide chart paper to operate continuously at a speed of $7 / 8$ inch per hour. The input channel drives a fiber tip pen fed by a disposable ink cartridge. The chart paper has a scale marked in increments of 1 percent of scale ( 0.05 inches of water column) with a range from 0 to 100 percent. The Canyon exhaust tunnel vacuum differential pressure transmitter is calibrated annually.

The maximum uncertainty of the read out versus actual conditions for an instrumentation loop is the sum of the uncertainty for each component in series within the loop. The building vacuum reading has a maximum uncertainty of \pm 3 percent of the instrumentation range or \pm 0.09 inches of $\mathrm{H}_{2} \mathrm{O}$. The glovebox vacuum reading has a maximum uncertainty of \pm 2 percent of instrumentation range or \pm 0.04 inches of $\mathrm{H}_{2} \mathrm{O}$. The maximum uncertainty of the glovebox vacuum reading with respect to the atmosphere is \pm 0.13 inches of $\mathrm{H}_{2} \mathrm{O}$. The canyon exhaust tunnel vacuum reading has a maximum uncertainty of \pm 2 percent of instrumentation range or \pm 0.1 inches of $\mathrm{H}_{2} \mathrm{O}$.

Attached are diagrams outlining the building vacuum, glovebox vacuum, and canyon exhaust tunnel vacuum instrumentation loops and associated maximum uncertainty. 


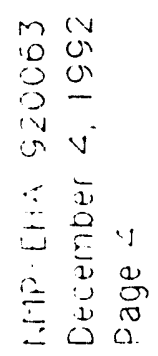

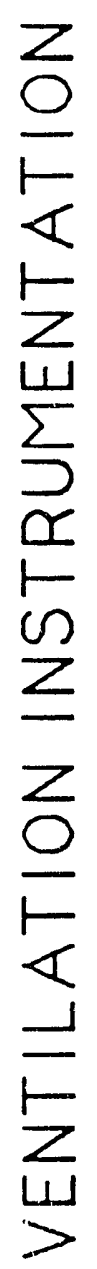
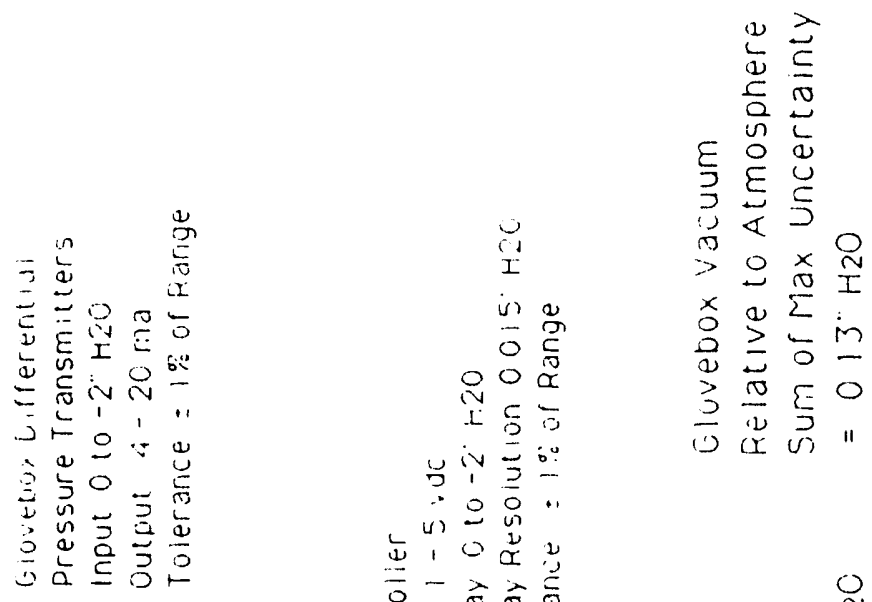

u iv $\equiv$ :

$\therefore 20$

文1 1001

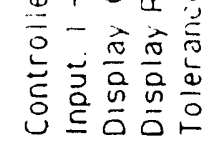
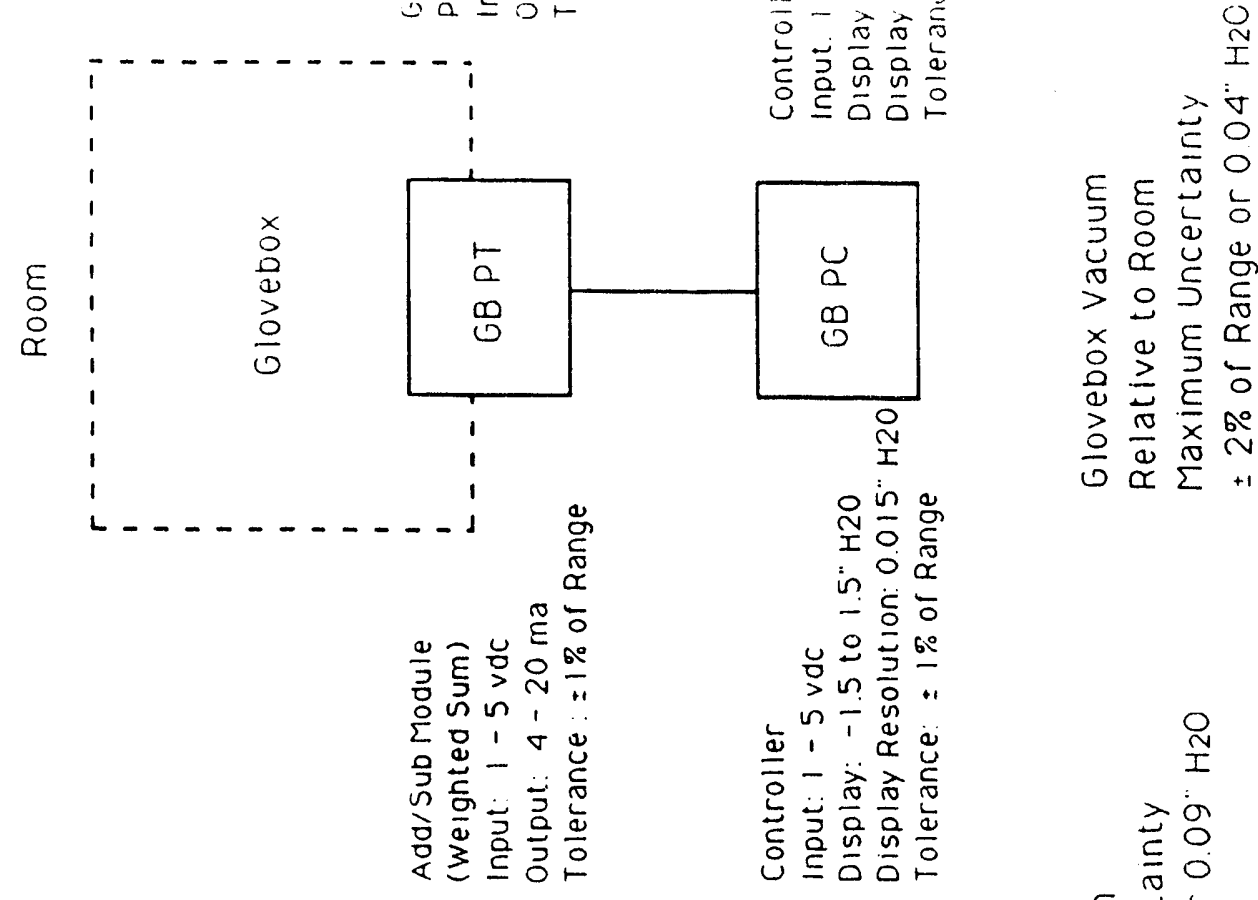

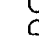

@

$\frac{U}{Z}$
$\frac{1}{1}$
I

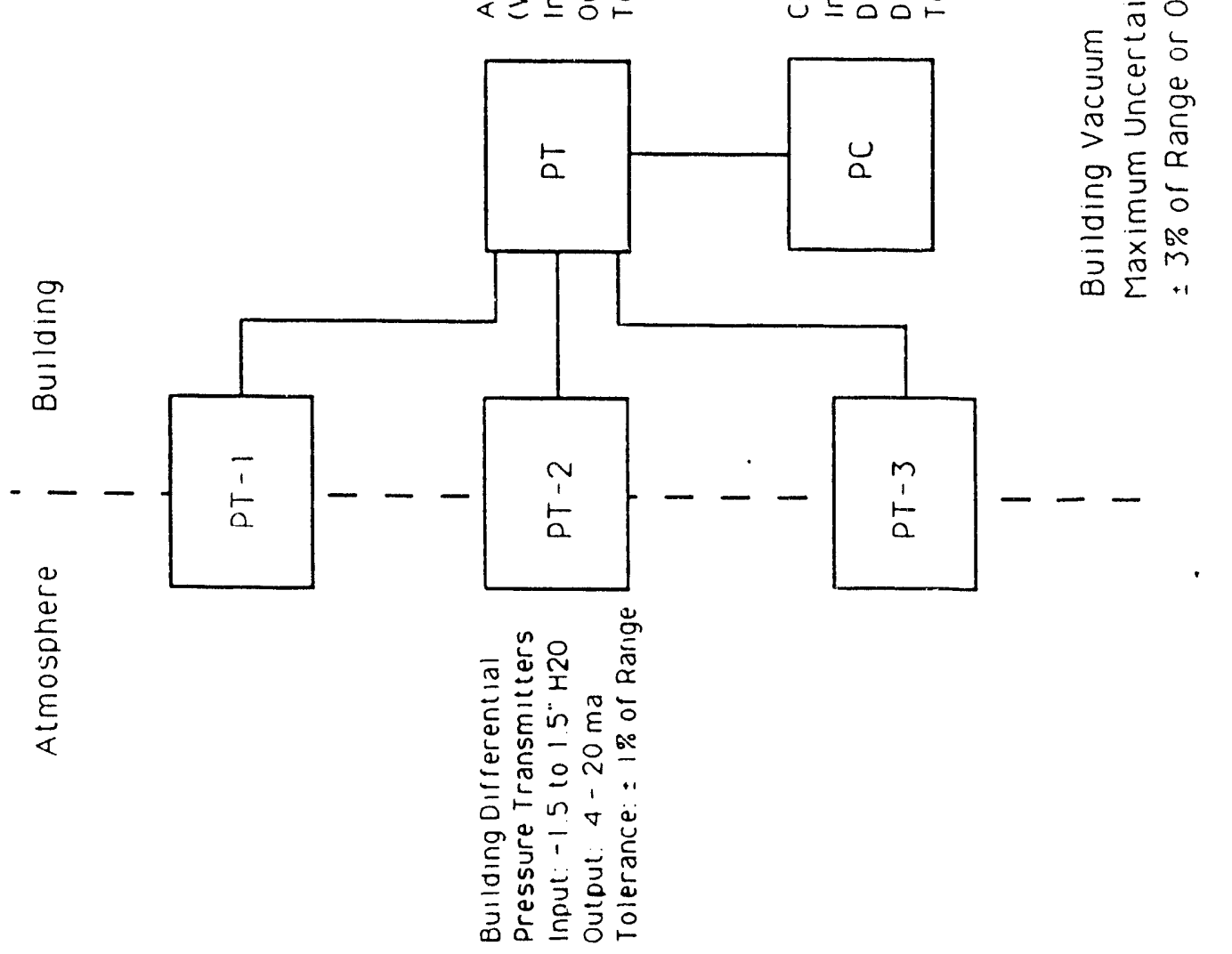

$\frac{\text { g }}{\frac{D}{\bar{D}}}$ 

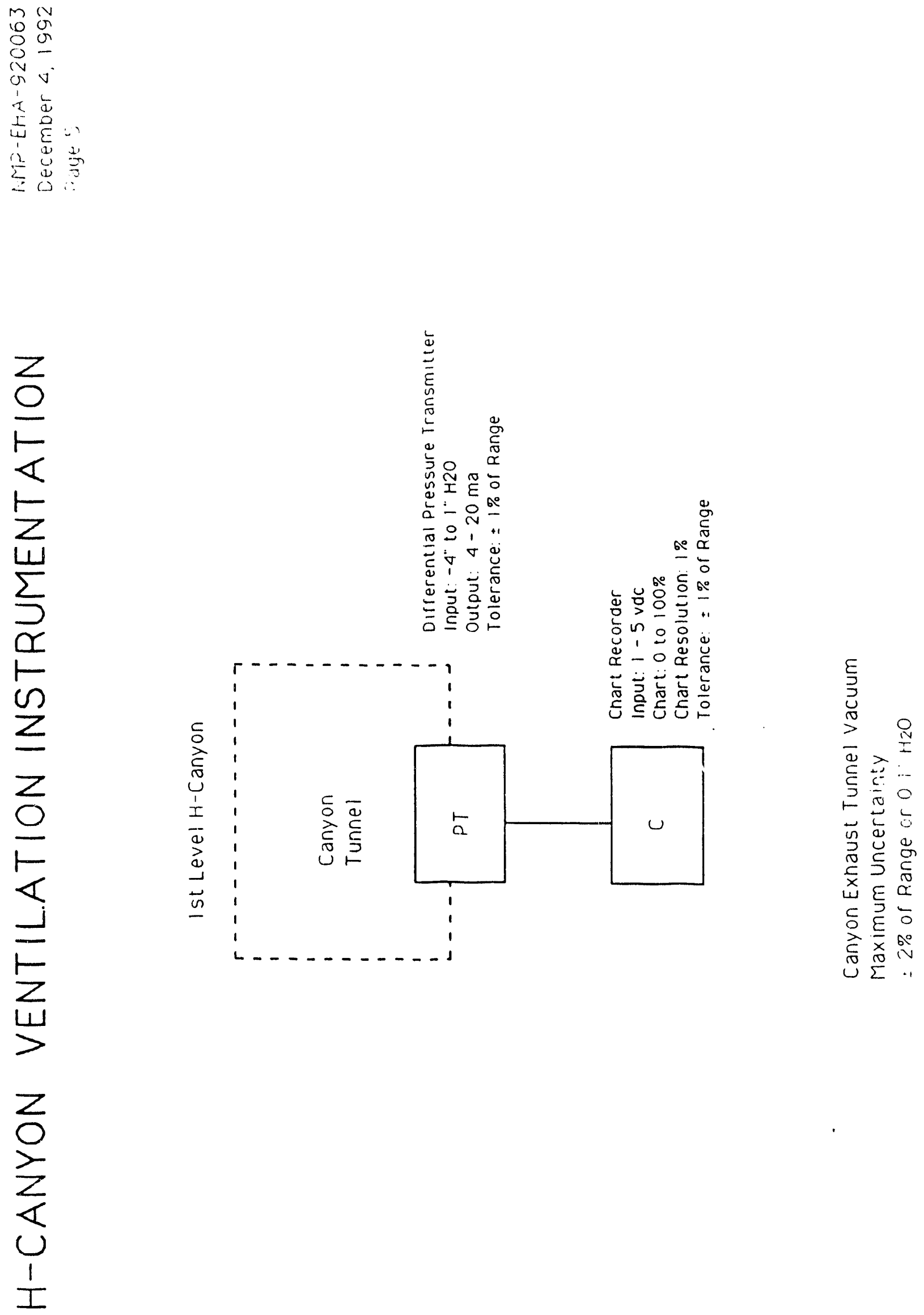
Additional Distribr:tion, "Maximum Uncertainty Estimation for the HB-Line Ventilation Instrumentation Readings (U)", NMP-EHA920063, 12/4/92

CC C. C. Mason, 703-A

S. M. King, 703-41A

R. T. Brock, 703-41A

W. H. Britton, 703-A

R. Maher, 703-A

P. W. Dickson, 703-F

J. G. McKibbin, 707-H

H. C. Wolf, 221-HBL

D. R. Johnson, 707-H

K. R. B. Menger, 221-10H

J. E. Dickenson, 703-F 

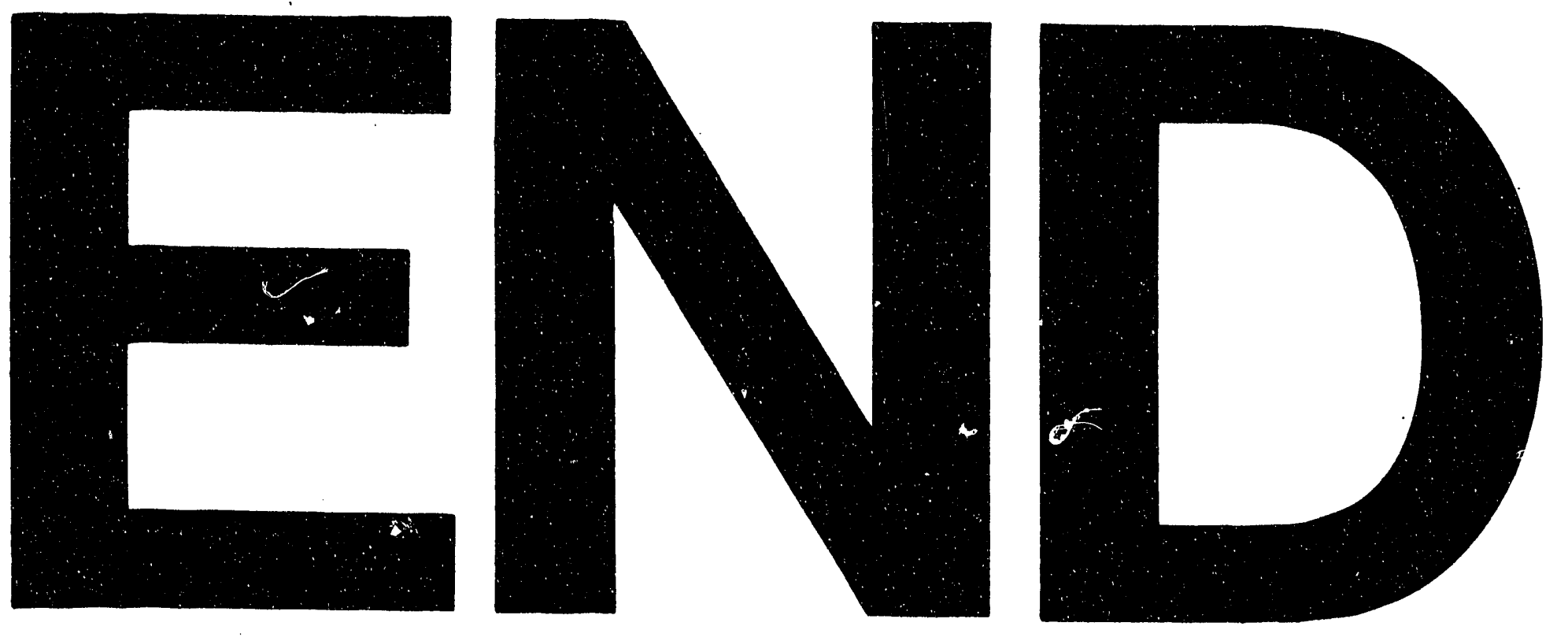

1
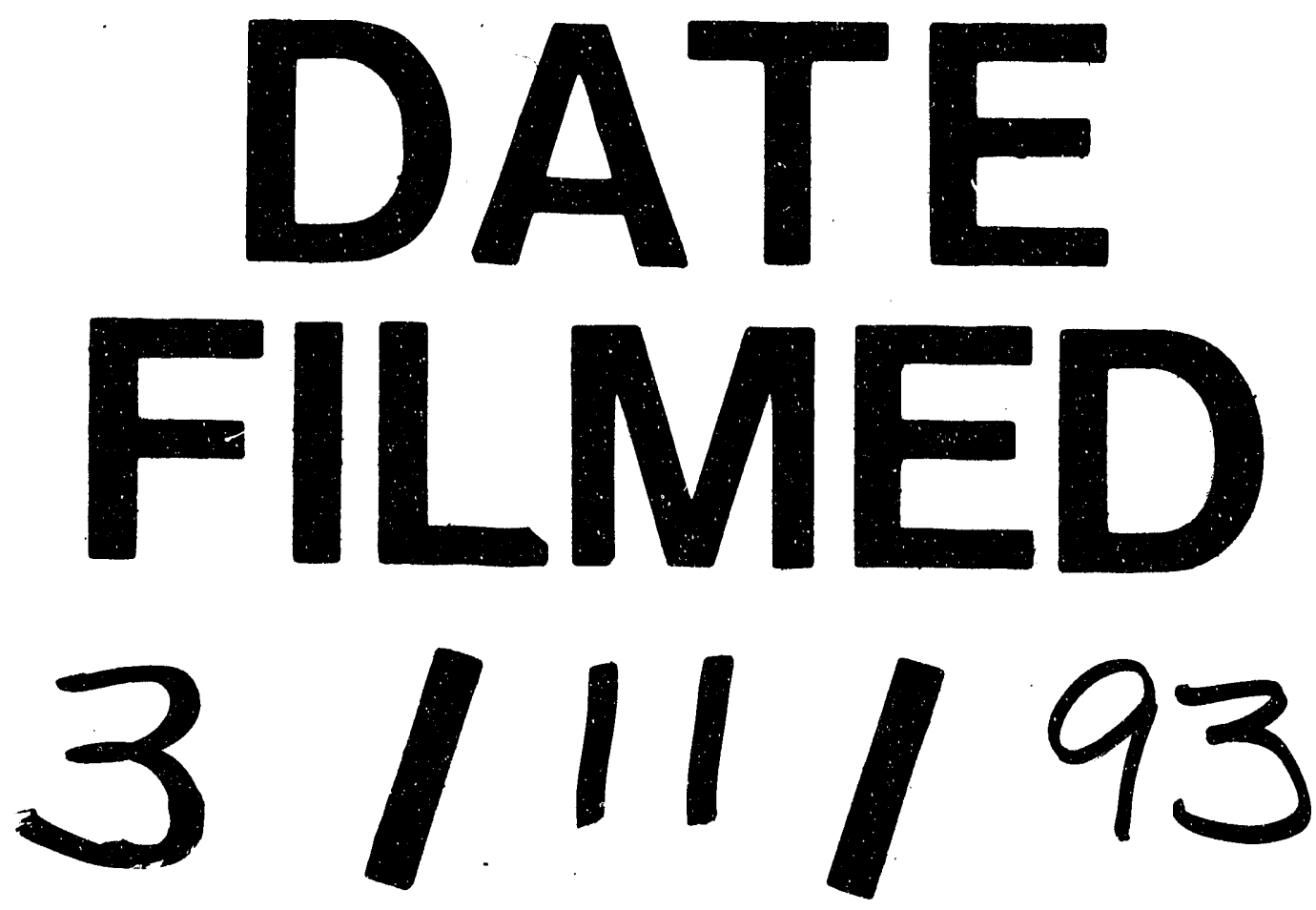
